Supporting Information for

\title{
Later Stage Melting of Isotactic Polypropylene
}

\author{
Junfang Shen ${ }^{1}$, Yufeng Zhou ${ }^{1}$, Yaguang $\mathrm{Lu}^{1}$, Binghua Wang ${ }^{1}$, \\ Changyu Shen ${ }^{1}$, Jingbo Chen ${ }^{1 *}$, Bin Zhang $^{1 * *}$ \\ ${ }^{1}$ School of Materials Science \& Engineering, Zhengzhou University, Zhengzhou \\ 450001, People's Republic of China \\ Corresponding Author E-mail: \\ "chenjb@zzu.edu.cn (J.Chen), \\ **binzhang@zzu.edu.cn (B. Zhang)
}



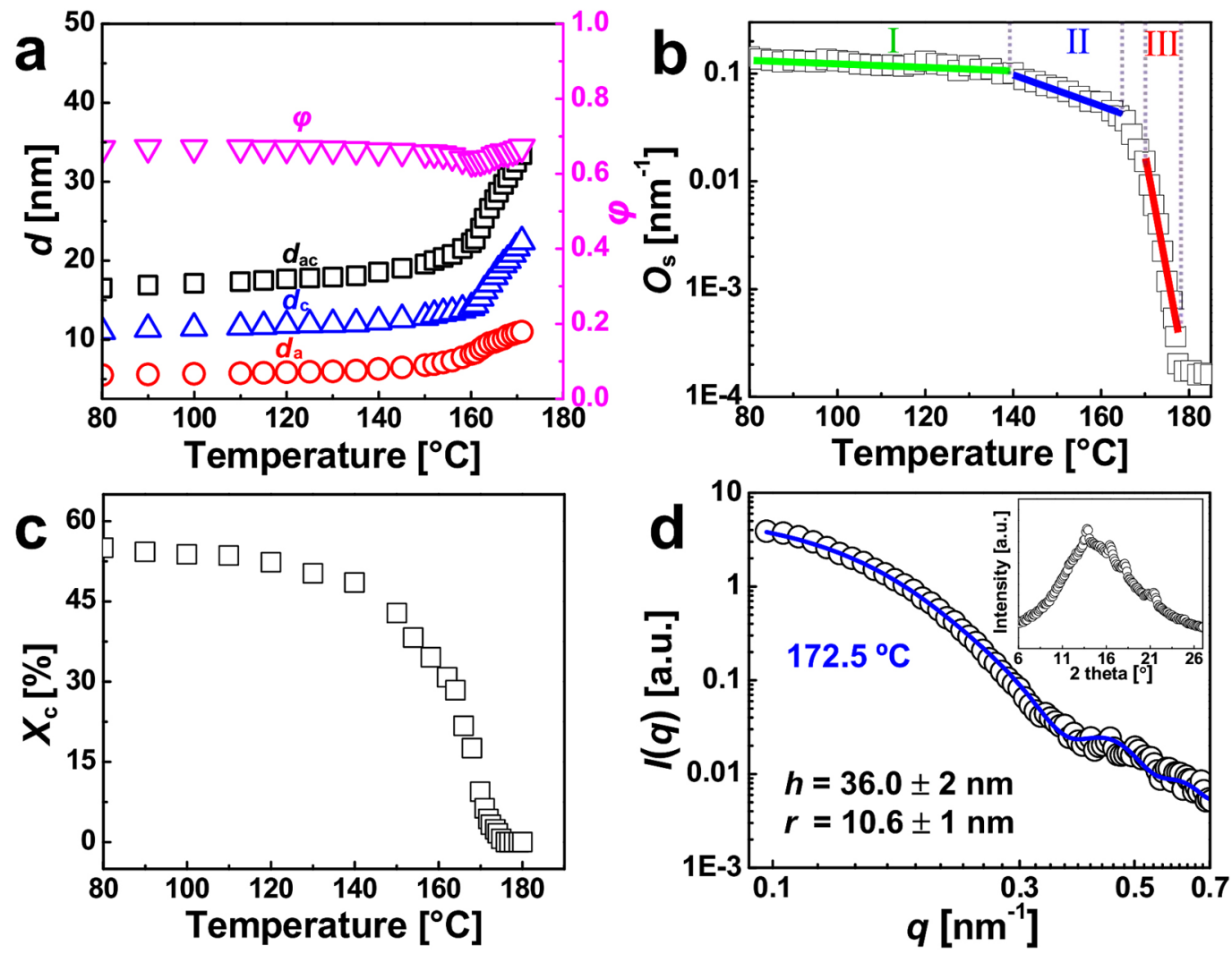

Figure S1. Melting behavior of iPP(F401) after purification. The temperature dependencies of (a) long period $d_{\mathrm{ac}}$, amorphous layer thickness $d_{\mathrm{a}}$, lamellar thickness $d_{\mathrm{c}}$, linear crystallinity $\varphi=d_{\mathrm{d}} / d_{\mathrm{ac}}$, (b) specific inner surface $O_{\mathrm{s}}$, and (c) crystallinity $X_{\mathrm{c}}$. (d) The fitting result for nanocrystals at $172.5^{\circ} \mathrm{C}$. The sample was firstly heated to $210^{\circ} \mathrm{C}$ for $10 \mathrm{~min}$, subsequently, it was cooled down to crystallization temperature $\left(T_{\mathrm{c}}=135^{\circ} \mathrm{C}\right)$ and isothermally crystallized for 60 min following by a cooling to ambient temperature at $10{ }^{\circ} \mathrm{C} / \mathrm{min}$. The data acquisition time for each scattering profile was $15 \mathrm{~s}$ with a waiting time of $1.8 \mathrm{~s}$ between adjacent profiles. The structural parameters of crystals were obtained during the melting process from room temperature to $200{ }^{\circ} \mathrm{C}$ at a heating rate of $1{ }^{\circ} \mathrm{C} / \mathrm{min}$. 

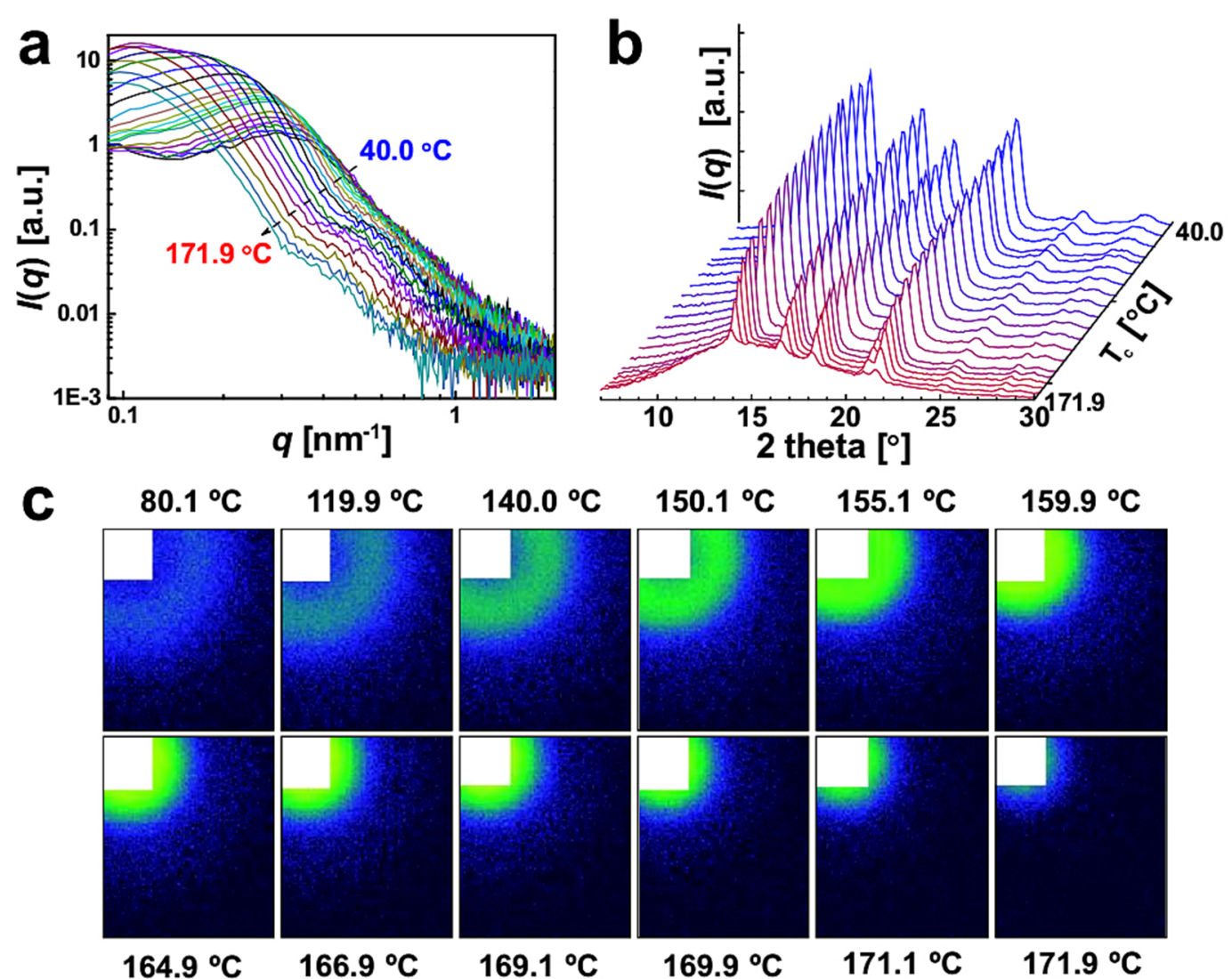

Figure S2. Representative (a) WAXS and (b) SAXS profiles obtained during heating of specimen at $1{ }^{\circ} \mathrm{C} / \mathrm{min}$ from 40 to $200^{\circ} \mathrm{C}$. (c) the corresponding $2 \mathrm{D}$ SAXS patterns. The sample was firstly heated to $210^{\circ} \mathrm{C}$ for $10 \mathrm{~min}$, subsequently, it was cooled down to crystallization temperature $\left(T_{\mathrm{c}}=\right.$ $135^{\circ} \mathrm{C}$ ) and isothermally crystallized for $60 \mathrm{~min}$ following by a cooling to ambient temperature at $10{ }^{\circ} \mathrm{C} / \mathrm{min}$. The data acquisition time for each scattering profile was $15 \mathrm{~s}$ with a waiting time of $1.8 \mathrm{~s}$ between adjacent profiles. 

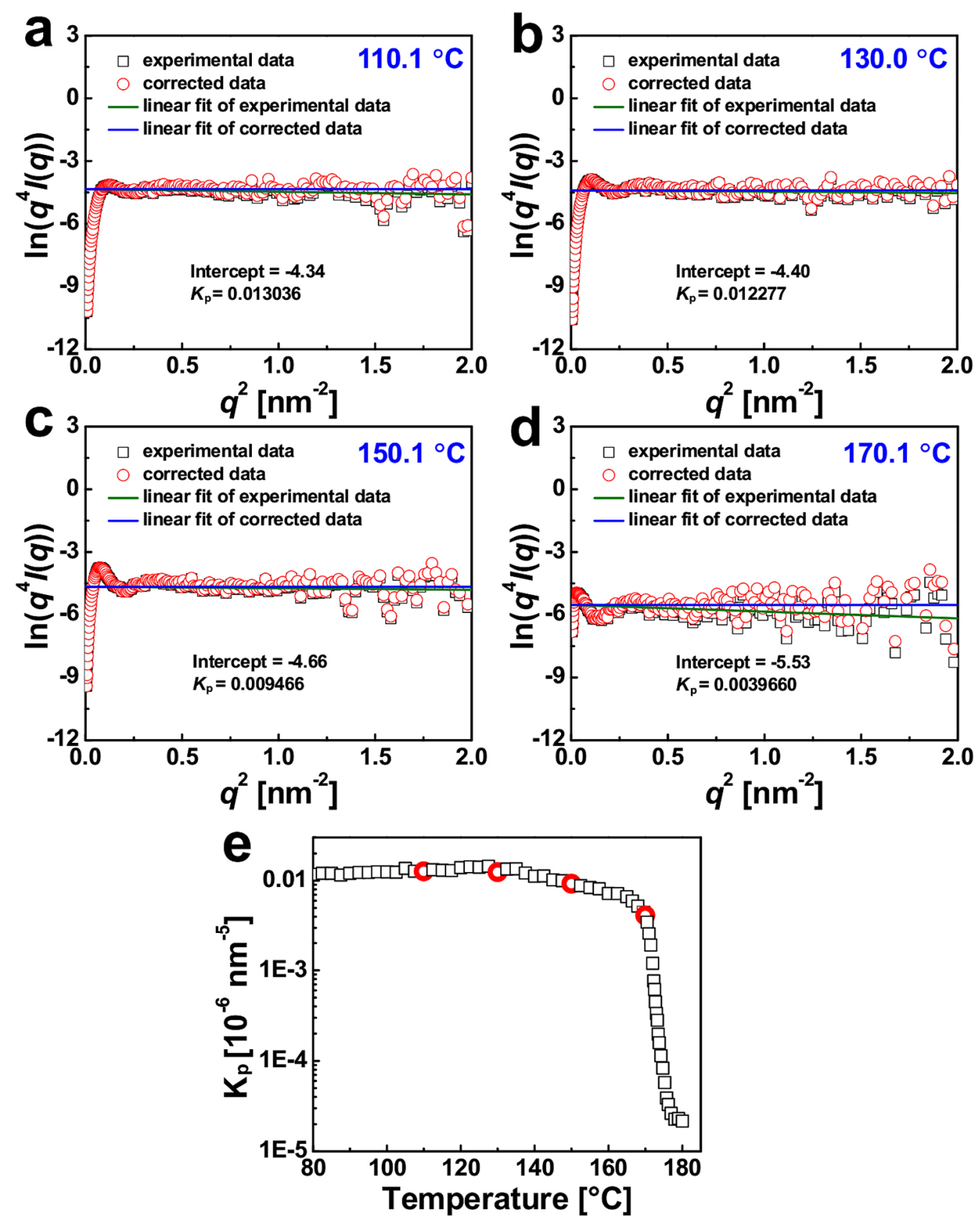

Figure S3. The detailed measurements of $K_{\mathrm{p}}$ for the SAXS data at (a) $110.1^{\circ} \mathrm{C}$, (b) $130.0^{\circ} \mathrm{C}$, (c) $150.1^{\circ} \mathrm{C}$ and (d) $170.1{ }^{\circ} \mathrm{C}$ during heating. SAXS profiles obtained during heating of specimen at $1{ }^{\circ} \mathrm{C} / \mathrm{min}$ from 40 to $210^{\circ} \mathrm{C}$. The specimen was firstly heated to $210^{\circ} \mathrm{C}$ for $10 \mathrm{~min}$, subsequently, it was cooled down to crystallization temperature $\left(T_{\mathrm{c}}=135^{\circ} \mathrm{C}\right)$ and isothermally crystallized for $60 \mathrm{~min}$ following by a cooling to ambient temperature at $10{ }^{\circ} \mathrm{C} / \mathrm{min}$. The data acquisition time for each scattering profile was $6 \mathrm{~s}$ with a waiting time of $1.8 \mathrm{~s}$ between adjacent profiles. 

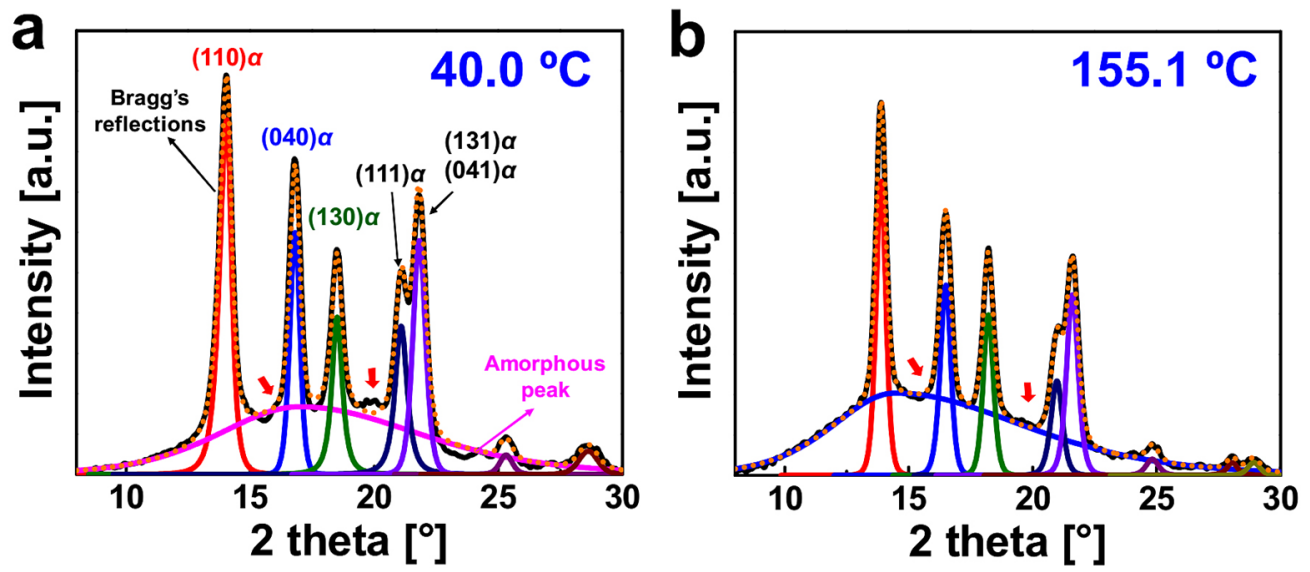

Figure S4. Fitting of WAXS profiles obtained at (a) $40.0{ }^{\circ} \mathrm{C}$ and (b) $155.1{ }^{\circ} \mathrm{C}$ during heating of iPP sample at $1{ }^{\circ} \mathrm{C} / \mathrm{min}$ from 40 to $200{ }^{\circ} \mathrm{C}$. The sample was firstly heated to $210{ }^{\circ} \mathrm{C}$ for $10 \mathrm{~min}$, subsequently, it was cooled down to crystallization temperature $\left(T_{\mathrm{c}}=135{ }^{\circ} \mathrm{C}\right)$ and isothermally crystallized for $60 \mathrm{~min}$ following by a cooling to ambient temperature at $10{ }^{\circ} \mathrm{C} / \mathrm{min}$. The data acquisition time for each scattering profile was $15 \mathrm{~s}$ with a waiting time of $1.8 \mathrm{~s}$ between adjacent profiles.
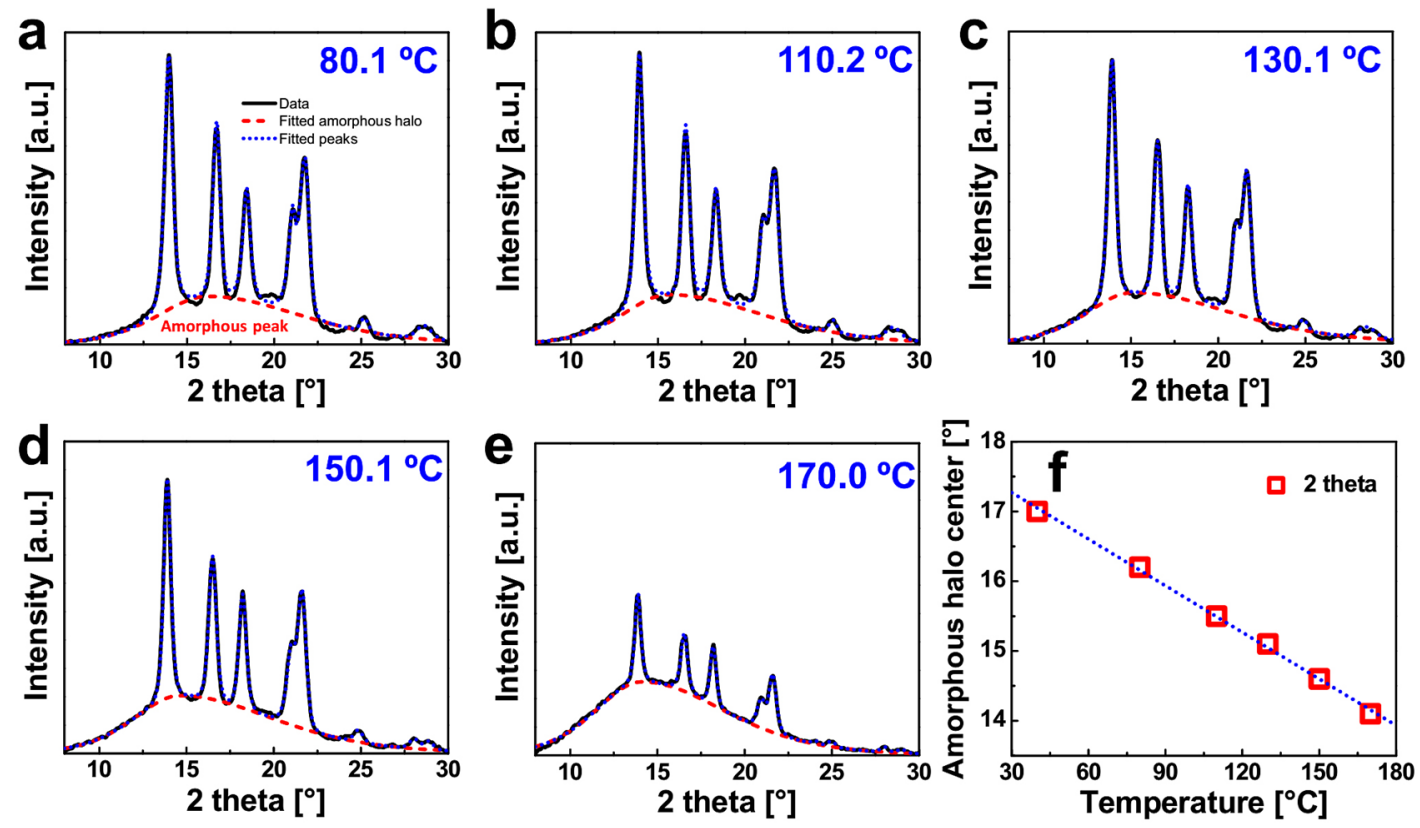

Figure S5. The definition of halo peak for the experimental data obtained at (a) $80.1{ }^{\circ} \mathrm{C}$, (b) $110.2{ }^{\circ} \mathrm{C}$, (c) $130.1{ }^{\circ} \mathrm{C}$, (d) $150.1{ }^{\circ} \mathrm{C}$ and (e) $170.0{ }^{\circ} \mathrm{C}$, (f) The temperature dependence of amorphous halo center during the heating process. Red dash line for the fitting result of halo peak and black solid line for global fitting result, respectively. The sample was firstly heated to $210{ }^{\circ} \mathrm{C}$ for $10 \mathrm{~min}$, subsequently, it was cooled down to crystallization temperature $\left(T_{\mathrm{c}}=135{ }^{\circ} \mathrm{C}\right)$ and isothermally crystallized for $60 \mathrm{~min}$ following by a cooling to ambient temperature at $10{ }^{\circ} \mathrm{C} / \mathrm{min}$. The data acquisition time for each scattering profile was $15 \mathrm{~s}$ with a waiting time of $1.8 \mathrm{~s}$ between 
adjacent profiles. WAXS profiles obtained during heating of iPP sample at $1{ }^{\circ} \mathrm{C} / \mathrm{min}$ from 40 to $200{ }^{\circ} \mathrm{C}$.
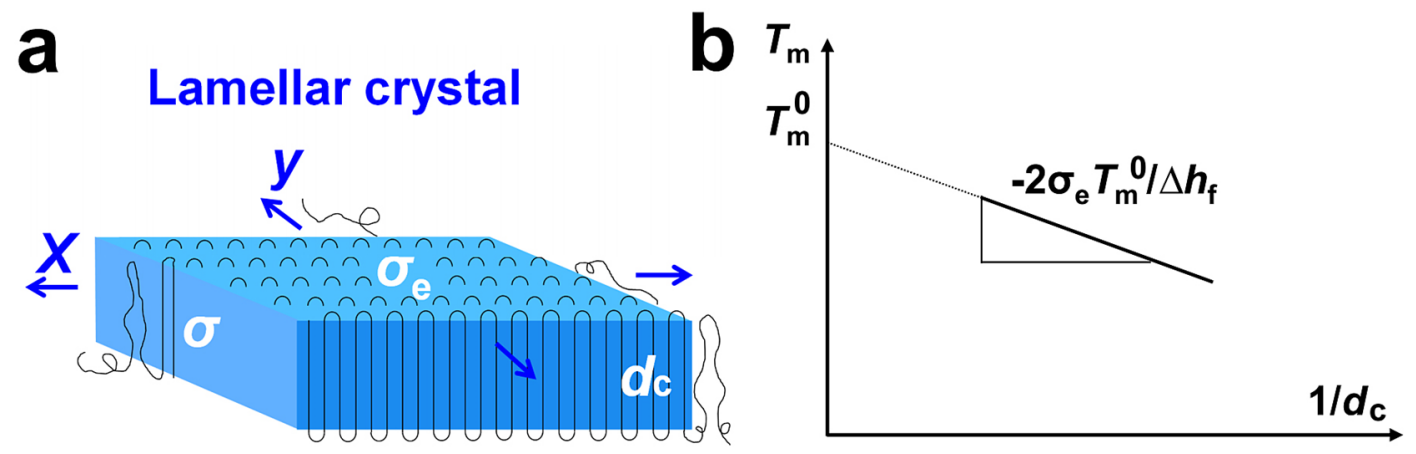

Figure S6. (a) Schematic of a chain-folded lamellar crystal in semi-crystalline polymers with lateral dimensions $X, Y$ and thickness $d_{\mathrm{c}} . \sigma$ and $\sigma_{\mathrm{e}}$ are the surface free energies associated with lateral and fold surfaces, respectively. (b) Schematic illustration of the extrapolation of the relationship between the melting temperature and reciprocal lamellar thickness. When the reciprocal lamellar thickness goes to zero (infinite thickness), the extrapolated melting temperature is the equilibrium melting temperature.

a

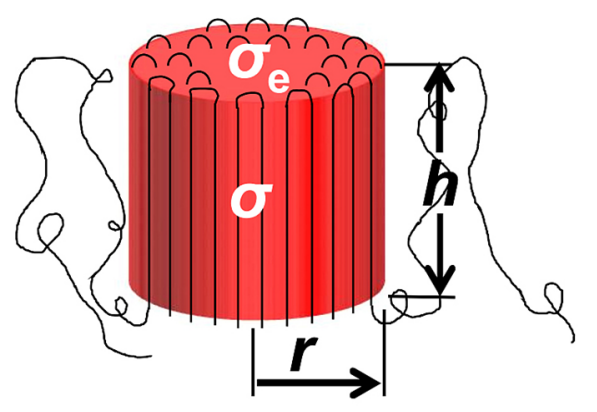

nanocrystal

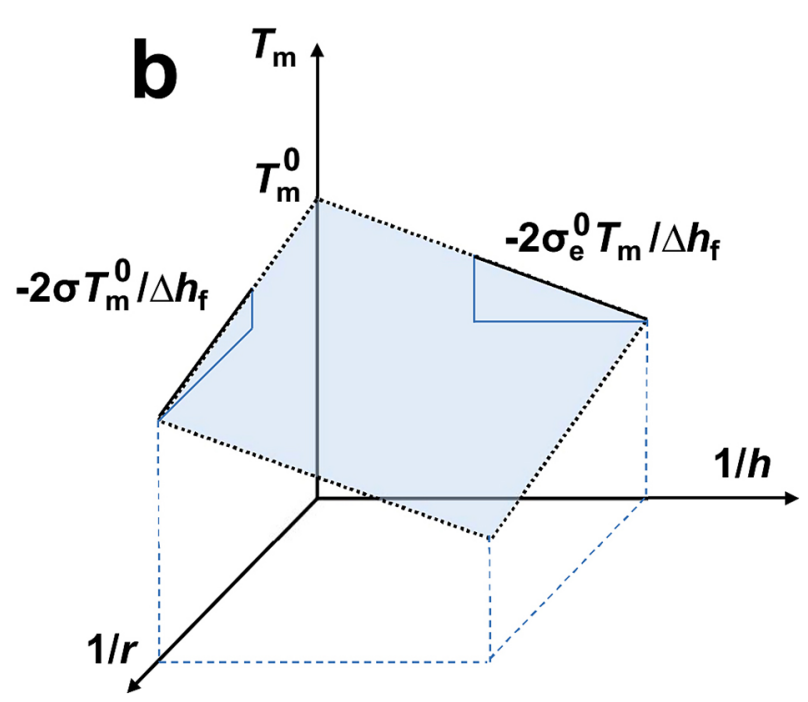

Figure S7. (a) Schematic of a chain-folded nanocrystal of semi-crystalline polymers with radius $r$ and height $h . \sigma$ and $\sigma_{\mathrm{e}}$ are the surface free energies associated with lateral and fold surfaces, respectively. (b) Schematic illustrations of the extrapolation of the relationship between the melting temperature, the reciprocal crystal radius and reciprocal height. When the reciprocal crystal lateral size and thickness go to zero, the extrapolated melting temperature is the equilibrium melting temperature. 

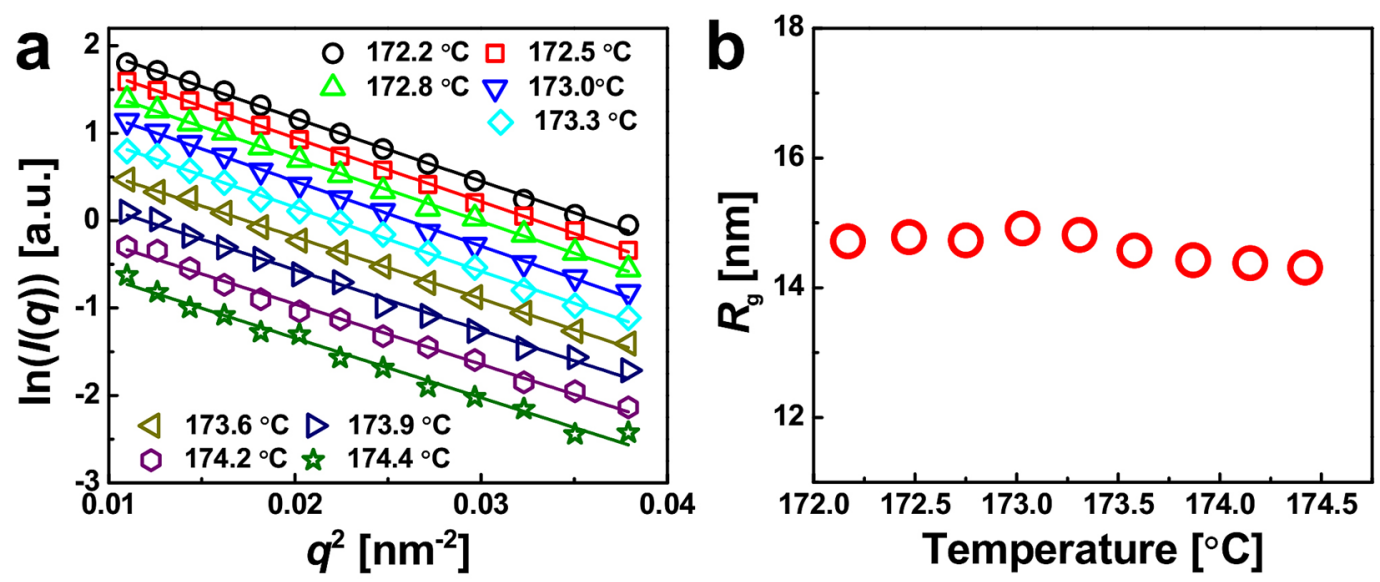

Figure S8. (a) Guinier plots for various crystallization temperatures at later stage of melting. (b) temperature variation of the radius of the isolated domain. The sample was firstly heated to $210{ }^{\circ} \mathrm{C}$ for $10 \mathrm{~min}$, subsequently, it was cooled down to crystallization temperature $\left(T_{\mathrm{c}}=135{ }^{\circ} \mathrm{C}\right)$ and isothermally crystallized for $60 \mathrm{~min}$ following by a cooling to ambient temperature at $10{ }^{\circ} \mathrm{C} / \mathrm{min}$. The data acquisition time for each scattering profile was $15 \mathrm{~s}$ with a waiting time of $1.8 \mathrm{~s}$ between adjacent profiles. SAXS profiles obtained during heating of iPP sample at $1{ }^{\circ} \mathrm{C} / \mathrm{min}$ from 40 to $200{ }^{\circ} \mathrm{C}$.
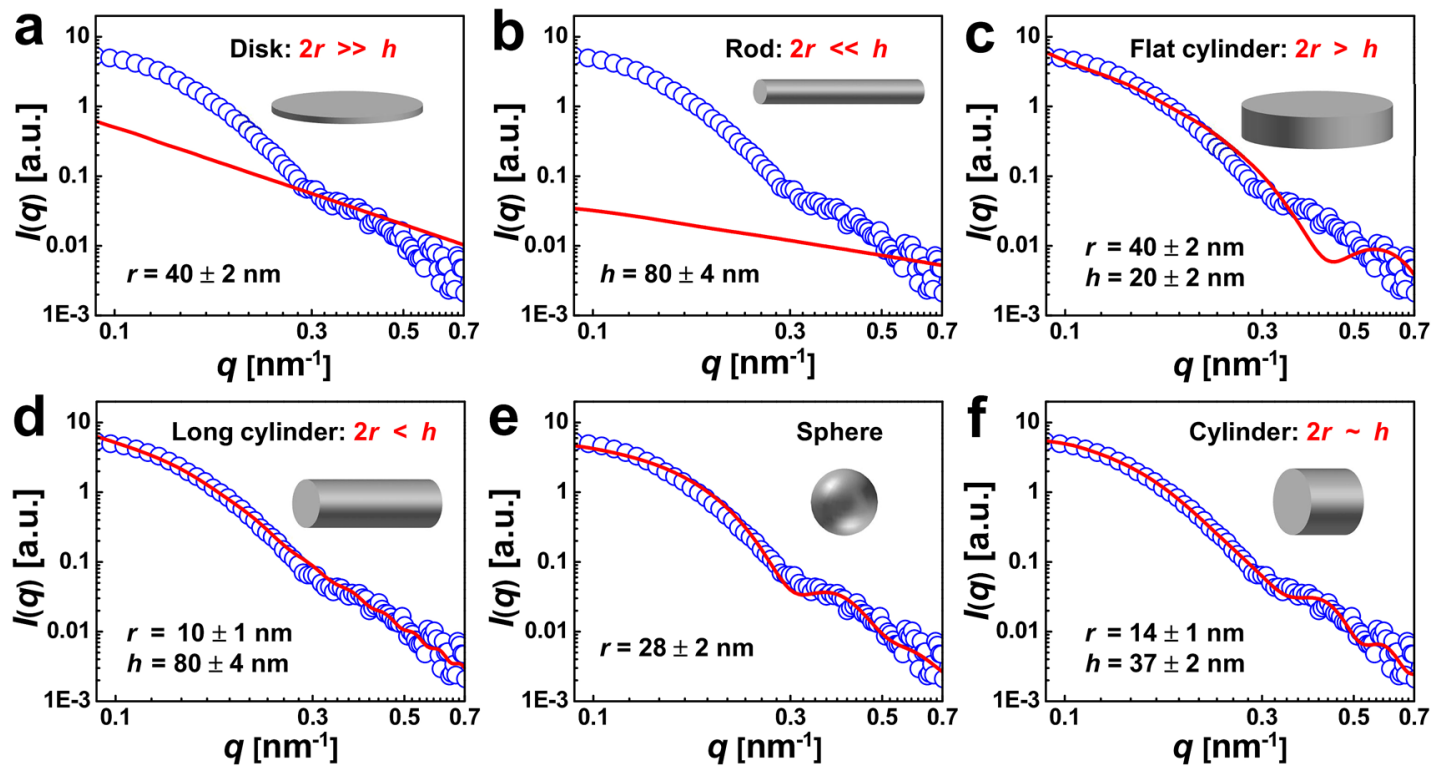

Figure S9. The fitting results of different models (a) Disk, (b) Rod, (c) Flat cylinder (d) Long cylinder, (e) Sphere, (f) Cylinder. SAXS profiles obtained at $172.2{ }^{\circ} \mathrm{C}$ during heating of iPP sample at $1{ }^{\circ} \mathrm{C} / \mathrm{min}$ from 40 to $200{ }^{\circ} \mathrm{C}$. The sample was firstly heated to $210{ }^{\circ} \mathrm{C}$ for $10 \mathrm{~min}$, subsequently, it was cooled down to crystallization temperature $\left(T_{\mathrm{c}}=135{ }^{\circ} \mathrm{C}\right)$ and isothermally crystallized for $60 \mathrm{~min}$ following by a cooling to ambient temperature at $10{ }^{\circ} \mathrm{C} / \mathrm{min}$. The data 
acquisition time for each scattering profile was $15 \mathrm{~s}$ with a waiting time of $1.8 \mathrm{~s}$ between adjacent profiles.

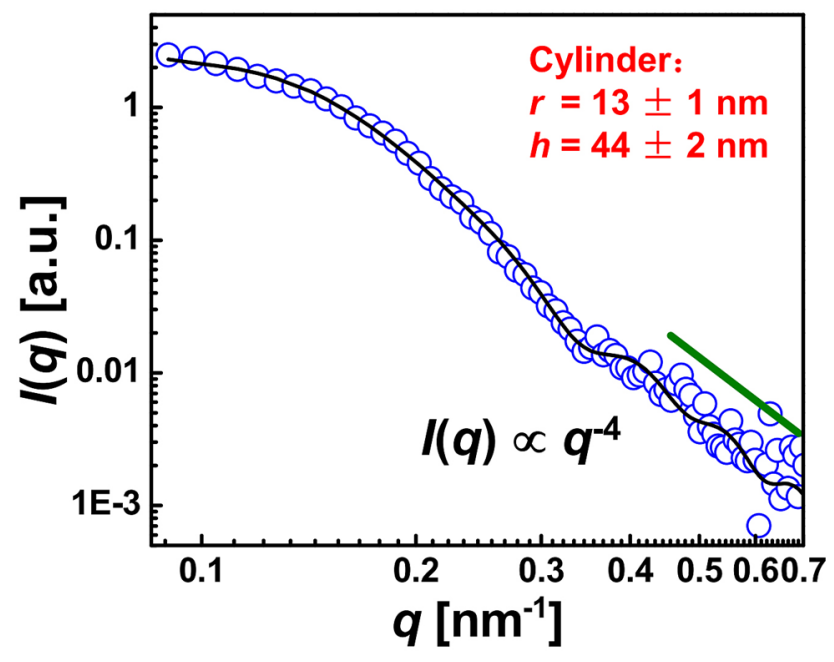

Figure S10. SAXS data (circles) and the fitted curve from an isotropic system of uncorrelated polydisperse particles. SAXS profiles obtained at $173.3{ }^{\circ} \mathrm{C}$ during heating of iPP sample at $1{ }^{\circ} \mathrm{C} / \mathrm{min}$ from 40 to $200{ }^{\circ} \mathrm{C}$. The sample was firstly heated to $210^{\circ} \mathrm{C}$ for $10 \mathrm{~min}$, subsequently, it was cooled down to crystallization temperature $\left(T_{\mathrm{c}}=135^{\circ} \mathrm{C}\right)$ and isothermally crystallized for 60 min following by a cooling to ambient temperature at $10{ }^{\circ} \mathrm{C} / \mathrm{min}$. The data acquisition time for each scattering profile was $15 \mathrm{~s}$ with a waiting time of $1.8 \mathrm{~s}$ between adjacent profiles.

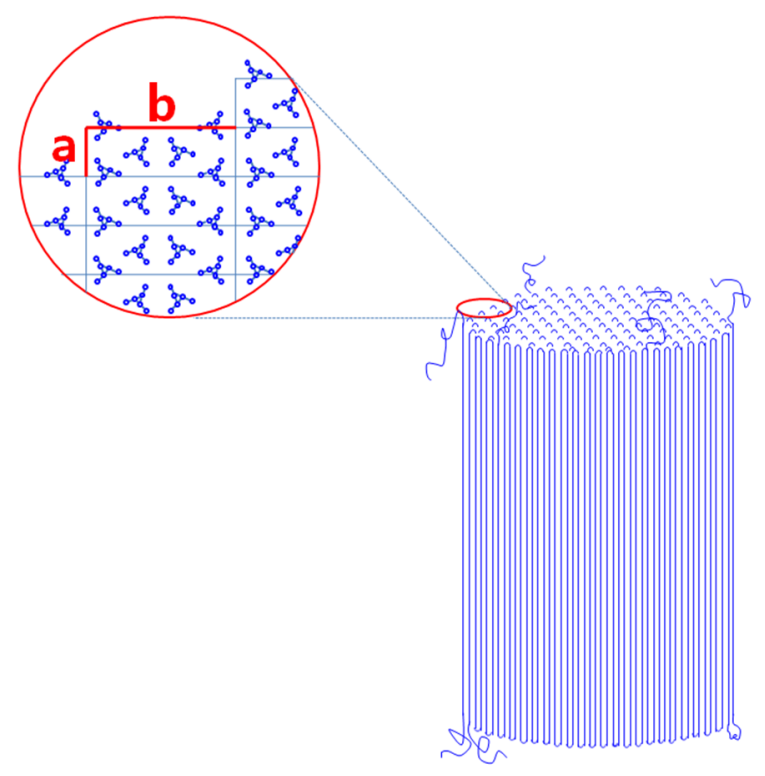

Figure S11. The diagrammatic sketch for survived nanocrystals. The unit cell of $\alpha$-form iPP is magnified in the circle in the upper left corner to visualize the molecular arrangement 